made, commencing at the onset or very early in the beginning of the disease, comparing the pulse-wave and the temperature-curve of the perfectly healthy with the slightly pathologic subject. This may lead finally to a definite and comprehensive understanding of these obscure facts, and may greatly assist the diagnostician, in connection with all the other signs and symptoms, to recognize early and obscure tuberculosis.

3033 Colorado Avenue.

\section{ELEPHANTIASIS, WITH A REPORT OF A CASE}

\section{JAMES PATTERSON, M.D. CHICAgo}

Elephantiasis in temperate latitudes is rare enough to deserve more than passing notice. Most cases reported are due to repeated erysipeloid attacks, tumors, granulomas, or extensive operative interference with the lymphatics of the affected area. Shattuck ${ }^{1}$ tells us of three cases of lymphatic elephantiasis in which repeated attacks of inflammation were the chief cause of the condition. Then Brault, ${ }^{2}$ while emphasizing the general causes suggested above, presents one case of this disease due to paratuberculosis, microscopic examination failing to reveal giant celis, or tubercle bacilli. Again, Thompson $^{3}$ records four cases, from one of which microscopic s e c tions were made and studied by Professol. James Ewing. This study showe? the usual picture of chronic edema; some hyperplasia of the malpighian layer, hypertrophy of the sweatglands, a $\mathrm{n}$ d a $\mathrm{n}$ atrophy of the hair-follicles. In 1912, H un te $\mathrm{r}^{4}$ gives a history of a woman who had never been outside the British Isles and whose condicion followed repeated attacks of cellulitis. Here again the microscope showed nothing but chronic edema. The same is true of the cases reported by Van der Veer $^{5}$ and Coenen. ${ }^{6}$ All these men are of the opinion that elephantiasis outside the tropics is due to recurrent attacks of cellulitis, tuberculosis, syphilis, tumors or extensive operative interference with the lymph drainage.

In the late autumn of 1912 I saw at Ely, Minn., with Drs. Ayres and Parker of that city a case of ele-

1. Shattuck: Boston Med. and Surg. Jonr., 1910. elxii, 107.

2. Brault: Arch. f. Dermat. u. Syph.. 1911. cx. 105.

3. Thompson : Tr. Assn. Am. Phys.. Philadelphia, 1911, xxvi, 145

4. Hunter, $W, K$. Note on a Case of Elephantiasis occurring in

This Country, Glasgow Med. Jour. 1912. Ixxviil. 166.

5. Van der Veer: Internat. Clin., Philadelphia, 1912, 22, 227.

f. Coenen : Berl. klin. Wchnschr., 1912, xlix, 902. phantiasis in a patient who had never been in the tropics. The history of the case is as follows:

Patient.-Mrs. M. K., aged 32, was born in Austria and lived there till 1903, when she and lier husband moved to Ely, Minn. Shortly after her arrival the disease began to make its appearance. Patient noticed a swelling of both legs and the abdomen, beginning in 1904, which gradually grew worse until she was practically completely disabled in 1909 . There is no history of cellulitis preceding this condition nor of any fever such as usually precedes a true tropical elephantiasis. ${ }^{7}$ The blood was not examined for filaria at any time.

The patient had no living children. Three pregnancies resulted in a still-born full-term fetus in 1904, still-born seven months' fetus in 1906, abortion of a four months' pregnancy in 1908. The history is negative otherwise. No cases of a similar nature are known by her husband and friends in that part of Austria from which they come. The patient died in the spring of 1913.

A partial necropsy showed a thickening of the abdominal wall, becoming greater from the umbilicus down to the pubes, where it measured $3 \frac{1 \% 2}{2}$ inches from skin where it measured $31 / 2$ inches from hypertrophic cirrhosis of the liver and a large quantity of ascitic fluid. Sections of the liver were not obtained, but sections from the thickened abdominal wall show an encapsulated filarial organism distributed throughout the deeper toxies as shown in the accompanying Aratwings. Many of them are calcified. So we have a case of filarial elephantiasis in a patient who has never been in regions in which that disease prevails. What variety of organism was present could not be deternined, bu t probably it is the filaria of Bancroft, the morphology of which is gone into at length by Fulleborn $^{8}$ and also by Foley. ${ }^{9}$ How this infection was acquired is a matter of speculation, but filariae have been found in the blood of the horse, ${ }^{10}$ in camels, ${ }^{11}$ and in dogs. ${ }^{12}$ Dogs bave also been inoculated with the filaria by means of the mosquito. ${ }^{12}$ So it is just possible that the definite relation between the incidence of filariasis and elephantiasis of which Daniels ${ }^{13}$ speaks is not entirely confined to the tropics and that some cases of elephantiasis in temperate climates are due to filariae.

I wish to express my gratitude to Drs. Ayres and Parker for their kindness in allowing me to present this case.

7 West Madison Street.

7. Lowe: Jour. Trop. Med., 1911, Yo. 6

8. Fulleborn: Beihefte z. Ärch. f. Schiff- u. Tropen-Hyg., 1913, xvii, 1-72.

9. Foley: Ann. de l'Inst. Pasteur, Paris, 1913, 27. 50

10. Harrington: Am. Vet. Rec., N. Y., 1912, xliii, 87 .

11. Pricolo: Centralbl. f. Bakteriol., 1912, 1xvii, 478. vi, 89 .

13. Daniels, C. W.: Discussion on Lymphatic Diseases in the Tropics, Brit. Med. Jour., 1908, ii, 1359. 